\title{
Epidemiology and Risk Factors for Community- Associated Clostridium difficile Infection: A Narrative Review
}

Lauren E. Bloomfield · Thomas V. Riley

Received: April 19, 2016 / Published online: July 1, 2016

(C) The Author(s) 2016. This article is published with open access at Springerlink.com

\begin{abstract}
Clostridium difficile infection (CDI) was once considered a primarily nosocomial concern. Emerging evidence from the last 20 years has highlighted a drastic shift in the known epidemiology of CDI, with disease outside of hospitals apparently occurring more frequently
\end{abstract}

Enhanced content To view enhanced content for this article go to http://www.medengine.com/Redeem/ 5AD4F0604753A603.

L. E. Bloomfield

School of Health Sciences, Flinders University,

Bedford Park, SA, Australia

L. E. Bloomfield

Western Australian Department of Health, Communicable Diseases Control Directorate,

Shenton Park, WA, Australia

T. V. Riley $(\bowtie)$

Department of Microbiology, PathWest Laboratory

Medicine, Queen Elizabeth II Medical Centre,

Nedlands, WA, Australia

e-mail: thomas.riley@uwa.edu.au

\section{T. V. Riley}

School of Medical and Health Sciences, Edith Cowan University, Joondalup Drive, Joondalup 6027, WA, Australia

\section{T. V. Riley}

School of Veterinary and Life Sciences, Murdoch University, South Street, Murdoch 6150, WA, Australia and causing severe disease in populations that were thought to be at low risk. This narrative review summarises potential pathways for infection outside of the hospital environment and highlights likely routes of transmission. Further, evidence is presented on potential risk factors for development of disease. Understanding the epidemiology of CDI outside of hospitals is essential to the ability to prevent and control disease in vulnerable populations.

Keywords: Animal reservoir/source; Clostridium difficile infection (CDI); Community-associated CDI; Epidemiology; Risk factors

\section{INTRODUCTION}

Clostridium difficile is a spore-forming, gram-positive, anaerobic bacillus, which is a frequent cause of antibiotic-associated diarrhoea, especially amongst hospitalised patients $[1,2]$. The spectrum of disease caused by $C$. difficile infection (CDI) can range from mild diarrhoea to severe conditions such as fulminant colitis and toxic megacolon resulting 
in death [1, 3]. In 2010, the Society of Healthcare Epidemiology of America (SHEA) identified the epidemiology, pathogenesis, treatment and prevention of infection with $C$. difficile as one of the five most important clinical challenges facing the discipline of Healthcare Epidemiology [4].

Historically, CDI was considered largely nosocomial, with exogenous acquisition from the healthcare environment considered the main source of colonisation or infection [5]. The capacity of $C$. difficile to cause disease in the community was reportedly recognised as early as 1982 [6], although this disease was still considered rare in this population only 20 years ago $[7,8]$. This article examines the literature on community-associated (CA) CDI and the emergence of $C$. difficile as a cause of significant disease outside of healthcare settings. Suggested routes of transmission, including human, animal, food and environmental sources, are explored. Understanding the interaction between hospital and community cases is paramount in determining the underlying drivers behind the apparent global increase in cases of CA-CDI.

This article is based on previously conducted studies and does not involve any new studies of human or animal subjects performed by any of the authors. Ethics approval was not required for this narrative review.

\section{Healthcare-associated vs. community-associated infection}

Defining what is considered healthcare-associated (HA)- vs. CA-CDI is essential in determining the validity of case classifications. Prior to an agreed definition of what 'community-associated' infection entailed, non-standardised definitions were applied by a number of authors [7, 9-13].
These resulted in misclassification due to a failure to determine hospitalisation history in cases presenting from the community [14].

Recommended standard case definitions were published by the European Society of Clinical Microbiology and Infectious Diseases (ESCMID) Study Group for C. difficile in 2006 [15] and, in early 2007, the Centers for Disease Control and Prevention (CDC) ad hoc C. difficile working group recommended similar case definitions [16]. These definitions have had wide acceptance and are commonly used to categorise cases into HA or CA. The definitions take into account the clinical and microbiological evidence to establish what a 'case' of CDI is and further elucidate whether a case should be classified as HA or CA. A summary of the accepted case definitions of CA- and HA-CDI is shown in Table 1.

The CDC working group noted that these definitions were "interim surveillance definitions and recommendations based on existing literature and expert opinion that can help to improve CDAD surveillance and prevention efforts" [16]. Although these were published as 'interim' definitions, they have not been updated since their release in 2007. The recently updated European Centre for Disease Prevention and Control (ECDC) C. difficile surveillance protocol has not altered these original definitions [17].

It is likely that current enhanced surveillance definitions can be improved. Current enhanced surveillance definitions attribute a case to a healthcare facility exposure if it occurred within 4 weeks of discharge and provided the case was in hospital for a minimum of $48 \mathrm{~h}$ (HAI CO) $[15,16]$. There are several limitations with this definition. The necessary minimum $48 \mathrm{~h}$ stay as an inpatient prior to diagnosis for an infection to be considered potentially HA may not be necessary, as prolonged exposure to $C$. difficile is 
Table 1 Clostridium difficile-enhanced surveillance definitions (Source: McDonald et al. [16])

\begin{tabular}{|c|c|}
\hline Classification & Definition \\
\hline $\begin{array}{l}\text { 1. Healthcare facility onset, healthcare } \\
\text { facility-associated infection (HO-HCFA) }\end{array}$ & A case with symptom onset more than $48 \mathrm{~h}$ after hospital admission \\
\hline $\begin{array}{l}\text { 2. Community onset, healthcare } \\
\text { facility-associated infection (CO-HCFA) }\end{array}$ & $\begin{array}{l}\text { A case with symptom onset in the community or } 48 \mathrm{~h} \text { or less after } \\
\text { admission to an HCF, provided that symptom onset was less than } \\
4 \text { weeks after the last discharge from an HCF. Community-onset, } \\
\text { HCF-associated cases should be attributed to the HCF from which the } \\
\text { patient was last discharged, providing the patient was an inpatient of } \\
\text { that HCF for more than } 48 \mathrm{~h}\end{array}$ \\
\hline $\begin{array}{l}\text { 3. Community-associated Clostridium } \\
\text { difficile-associated disease (CA-CDAD) }\end{array}$ & $\begin{array}{l}\text { A case with symptom onset in the community or } 48 \mathrm{~h} \text { or less after } \\
\text { admission to an HCF, provided that symptom onset was more than } \\
12 \text { weeks after the last discharge from an HCF }\end{array}$ \\
\hline 4. Indeterminate & $\begin{array}{l}\text { A case who does not fit any of the above criteria for an exposure setting, } \\
\text { e.g. a patient who has symptom onset in the community but who was } \\
\text { discharged from the same or another HCF } 4-12 \text { weeks before } \\
\text { symptom onset }\end{array}$ \\
\hline 5. Unknown & $\begin{array}{l}\text { A case for whom the exposure setting cannot be determined because of } \\
\text { lack of available data }\end{array}$ \\
\hline
\end{tabular}

not required for infection, and potential sources of acquisition should be assessed in light of what is probable, possible or unlikely. Further evidence is needed to determine whether this minimum $48 \mathrm{~h}$ stay may be resulting in misclassification of HAI CO cases as CAI cases.

Some patients frequently visit the hospital for day procedures (e.g. chemotherapy and dialysis) and, as a result, have not had a length of stay more than $48 \mathrm{~h}$ prior to diagnosis. With frequent contact with the hospital environment (which previous studies have shown can be contaminated with $C$. difficile spores [18]) up to 3-4 times per week, ruling out the hospital as a source of acquisition may result in misclassification.

There are other circumstances under which application of the current enhanced surveillance definitions may be more likely to result in misclassification. One group is 'hospital in the home' (HITH) patients, who are provided hospital care via in-home medical visits, however are considered 'inpatients' of the hospital for this period for the reporting of bed days, and often in the reporting of other HA infections (i.e. central line-associated bloodstream infections). While considered inpatients for reporting purposes, these cases reside in their home for the duration of their treatment, and therefore acquisition of the infection has occurred outside of the hospital setting. HITH patients should not be considered inpatients for the purposes of surveillance, and infections occurring in these populations should be classified CAI.

In addition, there is little evidence concerning the number of HAI HCFO cases who may have been colonised on admission to hospital and only developed disease after being exposed to antimicrobials as part of their 
medical management. The rates of colonisation in 'healthy individuals' in the community are relatively low [19, 20]; recent data from a Canadian study suggest approximately $5 \%$ of patients admitted to hospital may be asymptomatically colonised [21]; however it is not clear how much this may vary across different regions. The work of Eyre and colleagues on over 1200 hospital cases of $C$. difficile over a 3.6-year period found that only $35 \%$ of cases were genetically related to at least one previous case [22]. These data support the hypothesis that asymptomatic colonisation on admission to a HCF has a significant impact on case numbers, even on those deemed HAI HCFO.

\section{LABORATORY TESTING FOR CLOSTRIDIUM DIFFICILE INFECTION}

Different diagnostic techniques used by laboratories have been highlighted as an area of concern when estimates of CDI prevalence are being conducted across multiple sites or countries [23]. Several diagnostic tests are available for CDI. There are advantages and disadvantages of various testing methods, often with trade-offs among sensitivity, specificity, turn-around time and costs. The available tests can loosely be grouped into those that detect the organism, those that detect the toxin and those that determine whether the organism is potentially capable of producing toxin by detecting toxin genes. A summary of the various testing methods is shown in Table 2.

The ability of different tests to detect different targets will clearly limit the ability of some studies to correctly determine which patients have active disease, which are asymptomatically colonised with toxigenic strains and which are harbouring non-toxigenic strains. To account for variable positive predictive values (PPVs) in populations with low prevalence, both ESCMID and the CDC recommend a two-step testing process, with a sensitive screening test as the first test $[24,25]$. Currently, no single test is suitable under all circumstances, and the outcome (e.g. diagnosis of infection, public health surveillance) must be taken into account when performing diagnostic testing.

\section{THE EMERGENCE OF COMMUNITY-ASSOCIATED CDI}

The emergence of, and risk factors for, CA-CDI have become major areas for research internationally [26-28]. Most literature focusing on CDI epidemiology is based on hospital data. Given the relatively high proportions of disease and risk factors within this population, this is not unexpected. Epidemiological studies of CA-CDI often include cases that have been detected at a healthcare facility. This undoubtedly skews the data, as hospital-identified (HI)-CDI may be more severe (i.e., severe enough to warrant presentation at a hospital for treatment) and under-represented, as an acute care facility is likely not the primary source of healthcare for many people living in the community who develop gastroenteritis symptoms.

The reported incidence of CA-CDI is likely to vary based on the study population and local awareness and testing practices. Hospital-based studies looking at cases of CA-CDI are suitable to compare prevalence across different regions, as this allows determination of the proportion of CA disease in populations presenting to acute care facilities. This method is more reliable than trying to determine the 
Table 2 Diagnostic methods for the detection of $C$. diffficile (adapted from Rupnik et al. [26])

\begin{tabular}{|c|c|c|}
\hline Diagnostic method & Advantages & Disadvantages \\
\hline Culture & Sensitive & $\begin{array}{l}\text { Does not differentiate toxigenic and non-toxigenic } \\
\text { strains } \\
\text { Slow }\end{array}$ \\
\hline $\begin{array}{l}\text { Antigen detection (glutamate } \\
\text { dehydrogenase }[\mathrm{GDH}] \text { ) }\end{array}$ & $\begin{array}{l}\text { High negative } \\
\text { predictive value } \\
\text { Fast }\end{array}$ & Non-specific (requires supplementary testing) \\
\hline Cytotoxin assay & $\begin{array}{l}\text { Sensitive } \\
\text { High specificity for } \\
\text { infection }\end{array}$ & Slow \\
\hline Enzyme immunoassay & Fast & $\begin{array}{l}\text { Low positive predictive value, particularly in population } \\
\text { with low prevalence }\end{array}$ \\
\hline Membrane assays & Fast & $\begin{array}{l}\text { Low positive predictive value, particularly in population } \\
\text { with low prevalence }\end{array}$ \\
\hline Real-time PCR & Rapid & Uncertain specificity for infection \\
\hline Toxigenic culture & High sensitivity & $\begin{array}{l}\text { Uncertain specificity for infection } \\
\text { Slow }\end{array}$ \\
\hline Toxin B gene detection & $\begin{array}{l}\text { High sensitivity } \\
\text { Fast }\end{array}$ & $\begin{array}{l}\text { Uncertain specificity for infection } \\
\text { High cost }\end{array}$ \\
\hline
\end{tabular}

relative incidence in a community, with methodological difficulties in determining catchment populations and testing often at the discretion of the referring physician [29], which may lead to under-reporting.

\section{Europe}

Under-diagnosis of CDI, particularly among community cases, has been noted in Europe $[30,31]$. This may be owing to lack of clinical awareness or non-sensitive laboratory diagnostic tests [30]. Early reports showed that even when CA-CDI was considered relatively uncommon, cases were being identified in individuals with no recent hospitalisation history or links to outbreaks in hospitals [32], suggesting a potential source of infection in the community.

Using a 90-day cut point for recent hospitalisation to define a case of 'probable community-acquired $\mathrm{CDI}^{\prime}$, a study using administrative data in the England over a 12-year period demonstrated an increase in both the rate and proportion of CAI [33]. The overall proportion of probable community-acquired CDI in this study increased from $7.1 \%$ to $13.5 \%$. Consistent application of the same definition for surveillance purposes is sufficient to demonstrate a real increase over time.

A recent multi-centre study across 97 hospitals in 34 European countries applied enhanced surveillance criteria to 506 CDI cases 
and found 70/506 (14\%) of cases were classified CA-CDI [34]. The proportion of CA-CDI varied markedly across countries, ranging from $0 \%$ to $82 \%$. As this was a hospital-based study, it is difficult to assess whether the patient population and testing practices had a major influence on rates from the limited information available.

\section{North America}

While CA-CDI is increasingly recognised in the USA, under-reporting is still suspected [35]. Some large-scale CA-CDI studies have been undertaken in the USA. A six-centre study in North Carolina published in 2010 reported a prevalence of CA-CDI of $20 \%$ [36]. In another multi-centre US study involving eight geographic areas and 10,342 cases, the reported prevalence of CA-CDI was 32\% [37]. A further important finding of this study was that one in four patients with CA-CDI was hospitalised within 7 days of diagnosis, representing a significant cost and burden to the healthcare system. Others have reported even higher rates of hospitalisation (up to 40\%) in CA-CDI cases [38].

Allard and colleagues surveyed 15 hospitals in Montreal 2005-2006 and, of 2297 cases of CDI, 599 (27\%) were classified as CA-CDI, at a rate of 32 cases per 100,000 person-years [39]. Similar rates were observed across one reporting year in another Canadian province (Manitoba) by Lambert and colleagues, who also reported a prevalence of $27 \%$ and a rate of 23.4 cases per 100,000 person-years [40].

\section{Other Regions}

There are few studies on CA-CDI outside of North America and Europe, perhaps reflecting an overall lack of $C$. difficile studies in general conducted in these regions. A recent Singapore-based, single-centre study found an overall prevalence of $13.6 \%$ CA-CDI [41], lower than rates reported in other regions but nonetheless reflective of CA disease being of concern in this region. A comprehensive study of CDI in all Australian jurisdictions was published in 2014, although CA case data were not available for all geographical areas [42]. From the data contributed by three states, Tasmania, Victoria and Western Australia, CA-CDI comprised $26 \%$ of all HI-CDI cases between 2010 and 2012 [42].

One Kuwait-based study investigated diarrhoea in 2584 outpatients [43]. Although this study was not set up to determine the proportions of CA-CDI and HA-CDI, 16 cases were identified over a 2-year period, none of which had been hospitalised in the previous 6 months [43]. These data suggest a low prevalence of CA-CDI (0.62\%) presenting to this particular facility. There are few data from South America or Africa describing CA-CDI. It is unclear whether CDI represents a smaller burden of disease in these regions, and there is a lack of public health awareness around the disease and a lower priority in terms of public health surveillance and activity or a combination of these and other factors.

\section{RISK FACTORS FOR COMMUNITY-ASSOCIATED CDI}

There are several established risk factors for CA-CDI. There are some similarities and differences between risk factors in CA and HA cases [44]. For HA-CDI, advanced age (>65), antibiotic treatment and co-morbidities are all recognised risk factors $[45,46]$. CA-CDI, on the other hand, is frequently documented as occurring in younger populations who lack 
these traditional risk factors [27, 47-51]. Susceptibility to infection to some extent appears to vary on a case-by-case basis; while some CA-CDI cases may have many established risk factors, others seemingly lack the most important exposures, reflecting our lack of understanding of this entity. The degree to which host factors influence susceptibility and outcomes in disease is still not clear at this stage. Building a risk profile for CA-CDI may assist primary care providers in identifying these cases in the community setting.

\section{Antibiotics and Gastric Acid Suppressants}

Antibiotic exposure is the most important risk factor for all CDI, including CA-CDI [13, 36, 52-55]. While a meta-analysis conducted in the USA, focusing on CA-CDI and antibiotics, supported recent antibiotic exposure being an important risk factor for developing CA-CDI [56], this was not uniform for all antimicrobials. Certain classes (clindamycin, fluoroquinolones and cephalosporins) presented the most significant risk, and others (e.g. tetracyclines) had no associated increased risk [56]. The discrepant risk associated with different classes of antimicrobials has been found by other researchers [7, 57]. A case-control study conducted in the UK also found that exposure to antibiotics in the previous 4 weeks, particularly multiple agents, was significantly more frequent among CA-CDI cases than controls [58].

Although an important risk factor, US studies on CA-CDI cases have found 32-36\% of those with a documented medication history had no previous antibiotic exposure in the preceding 3 months [59, 60]. Further international studies have shown larger proportions (43-65\%) of CA-CDI cases compared to HA-CDI cases had no previous antibiotic exposure [61-64]. Thus antibiotics have an important, but perhaps not essential, role in CA-CDI, and other yet to be determined factors may play a role. Healthcare providers in the community should be cognisant of potential for CDI cases presenting with no prior history of antimicrobial use or hospitalisation.

Several studies have examined the use of gastric acid suppressants and their relationship with CDI [60, 65-67], with varying estimates of risk for CA-CDI (including nil significant findings) [68]. The use of PPIs appears to be particularly significant for the subset of CA-CDI that is not associated with prior antimicrobial exposure [60], indicating that the disruption to the microbiota, which occurs following exposure to a PPI [69-71], may be sufficient to cause disease in the absence of antimicrobial therapy.

\section{Co-morbidities}

CDI is a significant problem in populations with inflammatory bowel disease (IBD) (including Crohn's disease), with a high incidence, severe disease and evidence of increasing rates over time [72-74]. As patients with a flare in their IBD have diarrhoea, this leaves open the possibility that this is being detected more in this group because of surveillance bias [48]. This is especially true among Crohn's patients, half of whom do not have colonic involvement in disease [75]. This is, however, unlikely to account for all of the recent increases in disease observed in IBD cases, with IBD patients appearing to have a different acquisition pattern from the general population, including increased susceptibility to a wider range of sources in the community [76]. There may also be an additional problem 
in that not all patients with an apparent flare in their IBD are being tested for CDI, leading to possible under-reporting of the problem.

Other co-morbid conditions are associated with increased risk of CA-CDI, including chronic kidney disease, immunodeficiency (through infection or drug therapy), malignant lesions and solid organ transplants [27, 77, 78]. Severe co-morbid conditions such as these increase the risk of CDI because of prolonged use of antimicrobials and frequent contact with healthcare facilities [27]. As current definitions require an inpatient stay of $>48 \mathrm{~h}$ prior to diagnosis in order to classify an infection as HAI, frequent, short-stay hospital visits (such as those for dialysis or chemotherapy) may not be captured in this determination.

\section{Contact with Children <2 Years of Age}

Identification of $C$. difficile from neonates has been long established; the first isolation of this organism in 1935 was from the stool of healthy infants [79]. Although relatively rare in healthy adults, asymptomatic colonisation with toxigenic $C$. difficile occurs commonly among neonates and children $<2$ years old [80-82]. Acquisition can either occur during the neonatal period or later on (between 4 and 6 months of age), which corresponds to the weaning period [80]. Risk factors for development of disease in children $<2$ years appear to differ from the rest of the population [83] and, as previously noted, true disease as opposed to concurrent carriage in diarrhoeal patients may be difficult to discern. More research is required to determine the scope of magnitude of CDI in this population [84].

CA-CDI occurs more frequently in females than males [85, 86]. A 2006 study conducted in Connecticut found females had nearly twice the incidence of CA-CDI as males [59], although no hypothesis was offered for this discrepancy. CA-CDI has also been described in increasing numbers of peripartum women, many of whom do not have any other predisposing factors $[87,88]$. Contact with infants $\leq 2$ years old is significantly associated with CA-CDI $[43,58,60]$, and children have been previously identified as potential reservoirs in the community [89]. As the usual primary care givers for neonates and young infants, the possibility that neonates are responsible for causing disease in women in the community warrants further investigation.

\section{TRANSMISSION OF CDI IN THE COMMUNITY}

As C. difficile has traditionally been treated as a nosocomial infection, much of the literature around transmission focuses on the hospital environment, extending into long-term and similar care facilities. The recognition of this organism as a cause of diarrhoeal illness in the community has driven more recent research efforts towards understanding the acquisition and transmission of $C$. difficile outside of the hospital setting.

In 2010, Otten and colleagues published a transmission model of CA-CDI as an initial step towards developing a risk assessment for this pathogen in the community [90]. The model contain eight infection states: susceptible, gastrointestinal exposure, colonised, diseased, deceased, clinically resolved colonised, relapse diseased and cleared, with directional transfers between the states (Fig. 1). The model represents a complex relationship between epidemiological states in which a susceptible individual lacking protective factors becomes exposed to the organism, which in some cases leads to a diseased state. Sources of exposure and risk factors for developing disease once 


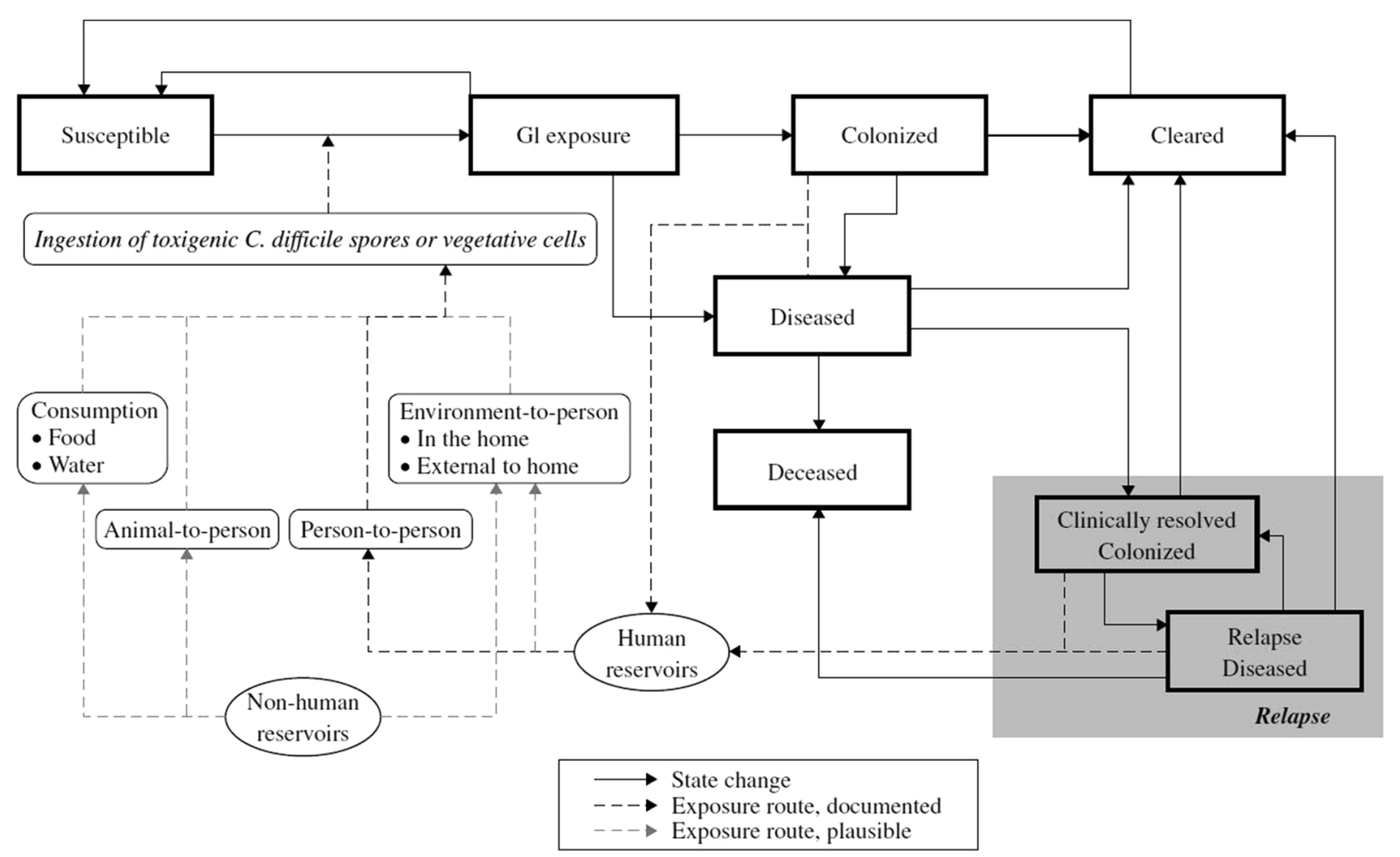

Fig. 1 Transmission model of community-associated C. difficile. Otten et al. [90]. Reproduced with permission

exposed are key areas for public health intervention in order to prevent disease and halt transmission.

Potential sources of exposure in the community are discussed in greater details below, but can be categorised broadly into consumption (ingestion of spores from a contaminated food product), person-to-person contact (transmission from another infected or colonised person), animal-to-person contact (transmission from an infected or colonised domestic or wild animal) and environment-to-person contact (ingestion of spores after exposure to a contaminated environmental source).

\section{Environment}

C. difficile contamination of households, even excluding those of known cases, appears to be relatively common, with Alam and colleagues finding an overall prevalence of $32.3 \%$ in household samples [91]. Toxigenic C. difficile has been found on boots/shoes [91], which suggests an introduction from contaminated soil from outside the home. Presence of spores on kitchen surfaces and refrigerators [92] may indicate transfer from food products. If the data collected to date on household contamination are representative of a typical household, people may expect to come into contact with C. difficile in their home environments on a regular basis.

The many reports on $C$. difficile outside of the hospital environment demonstrate that this organism is ubiquitous in natural settings, including soils [93-95] and waterways [93, 96], and inevitably present in environments where human faecal matter is treated such as waste water treatment plants [97, 98]. In addition, 
treated animal effluent used to irrigate agricultural products, and animal manure used for fertiliser, are other potential environmental sources $[99,100]$, with treatment practices not sufficient to eliminate the spores from the end product. Thus, there are large numbers of potential environmental sources for CA-CDI. Highly discriminatory typing methods may help to narrow down potential local environmental sources, including assessment of the ability of water treatment processes to remove spores and prevent further spread in the environment.

The significance of finding low absolute counts of $C$. difficile in environmental samples is unclear-while the 'infectious dose' remains unknown, detection in any number of sources may or may not be of public health significance [100]. It is likely that people are coming into regular contact with a small number of $C$. difficile either inside or outside of their home, which are rarely capable of causing disease unless the individual has a highly compromised gut flora. Discrepant individual practices around hand hygiene, particularly through hand washing before eating, may also impact on the significance of environmental contamination and the possibility of disease development.

\section{Animals}

One potential source of $C$. difficile transmission outside of the hospital environment is via animals. Although many clostridia cause disease in both humans and animals, these have not traditionally been considered zoonotic agents [101]. Molecular studies have, however, demonstrated common $C$. difficile isolates in production animals, companion animals and humans [102-107], particularly ribotype (RT) 078. As in humans, diarrhoea and C. difficile colitis have long been associated with antimicrobial therapy in animals [108]. Outbreaks of CDI have been reported at veterinary hospitals, affecting hospitalised dogs [109].

This opens the possibility of $C$. difficile sources for human infection in production (food) animals, companion animals and native/wild animals. As in neonatal humans, many young animals are colonised by $C$. difficile, which is displaced as the microflora matures [110]. Unlike humans, neonatal piglets develop severe diseases including diarrhoea and respiratory distress and demonstrated high levels of morbidity and mortality [110-112].

C. difficile has been documented in both healthy and diseased animals [113]. Recovery methods may account for variation in prevalence across studies $[114,115]$. The diseased status, age and species of animal also influence the reported prevalence [113, 116-118]. Production (food) animals are a widely studied group with $C$. difficile isolated from pigs, cattle and poultry [115].

In North America, CDI is now considered the most significant cause of neonatal diarrhoea in swine [119]. Production animals have historically been given broad-spectrum antimicrobials mixed in with feed as a prophylactic measure for infectious disease and as a growth promoters [120, 121]. The use of antimicrobials alters the microflora in livestock as it does in humans, leaving them susceptible to CDI. Once the organism is introduced to a herd, a large number of susceptible animals living in close quarters can rapidly become infected. CDI in production animals is of concern to industry because of potential growth delays in infected herds [122], loss of stock [123] and potential contamination of meat and dairy products, which may damage consumer confidence. 
Piglets can become colonised within an hour of birth, in the absence on antimicrobial treatment [124], perhaps a reflection of extensive environmental contamination. Keessen and colleagues demonstrated widespread aerial dissemination of $C$. difficile on a pig farm, with personnel activity contributing to an increase in numbers [125]. While the consequences of these findings for human health are not clear, detection of $C$. difficile occurred $20 \mathrm{~m}$ from the facility that raises the potential for wider contamination of the surrounding environment.

Common strains are reported in both animal populations and human isolates within the same geographical region [126-128]. Common strains being found in both humans and production animals leaves open the possibility that transmission is occurring from human to animal rather than the alternative. A small study conducted by Keessen and colleagues among pig farm workers found daily to weekly contact with pigs vs. monthly to less than yearly contact was significantly associated with an intestinal presence of $C$. difficile $(p=0.003)$ [129]. These data support the alternative hypothesis, with workers more likely to be colonised via frequent contact with the animals and their environment.

In addition, the organism has been isolated from companion animals [130-132] and their role as a reservoir of infection also requires further investigation. Wild (native) animals have been investigated and may play a role spreading $C$. difficile in the environment $[133,134]$. The detection of $C$. difficile in animal populations and the similarities between strains found in both humans and animals [126, 128] are suggestive that transmission between humans and animals is occurring, either directly or indirectly. Evidence that certain RTs such as RT 078, which are prevalent among animals, are now causing disease in increasing numbers in humans [104, 106] implies that transmission is occurring from animals to humans.

While animal-human or human-animal transmission is biologically plausible, a common source in the environment that allows transmission to both groups is an equally valid suggestion. The ubiquity of $C$. difficile in the environment supports this hypothesis. In the case of wild animal populations, it seems more plausible that the presence in these animals is indicative of $C$. difficile present in the environment (e.g. via contamination from treated waste) rather than a route of human-animal transmission [133].

In order to establish $C$. difficile as a zoonotic organism, research must establish an epidemiological link between animals and humans who do not share a common environment that may be a common source of infection. The most likely scenario in which this could occur is via the food chain or via water systems contaminated with the excrement of colonised or infected animals. Monitoring the prevalence of $C$. difficile in animal populations is useful in veterinary medicine and may further inform decisions on the use of antimicrobials in this population. Moreover, longitudinal analysis of predominant strains in animals is required to establish links with changes to strains causing disease in human populations.

\section{Food}

The potential for $C$. difficile to act as a foodborne pathogen undoubtedly exists, with several authors examining this potential link. The majority of studies have focussed on retail meats, especially beef, pork and poultry [135-139]. Presumably the detection of genetically similar strains in animal herds and 
humans has led to an increased awareness of the potential for $C$. difficile as a foodborne pathogen. The potential for secondary contamination of vegetables, e.g. onions and salads, has been explored to a lesser extent, despite early evidence of these foods as a potential source [93].

RTs 078 and 027 have dominated meat prevalence surveys in North America [135, 140-142]. This aligns with the common RTs from animal studies and suggests that meat is being contaminated at some point in processing rather than from another external source. Although not all RTs were able to be matched to reference laboratory samples, matches between RTs found in food samples and local human cases have been reported [137, 143, 144]. A lack of standard typing information across all studies highlights current inadequacies in nomenclature in the international literature and the impact this can have on identifying significant strains across regions.

The presence of toxigenic spores on ready-to-eat foods including meat and vegetables as well as the demonstrated potential for spores to survive freezing and cooking processes $[145,146]$ suggests that ingestion of spores from contaminated food products and subsequent infection of a susceptible host is a plausible scenario. In addition, ribotyping data show common strains in human and animal infection [126, 128] although further whole-genome sequencing will be required to definitively prove strain relatedness.

Currently, there is insufficient epidemiological evidence linking the consumption of contaminated food to increases of CA-CDI. Unlike other foodborne outbreaks, there are a number of factors that may mediate the development of disease. Unlike salmonellosis or another equivalent gastrointestinal pathogen, exposure to the organism, even in a large group of people, may not result in many or even one case of infection.

With foodborne pathogens, the infectious dose is of interest. This has not been established for $C$. difficile, and indeed it is not clear if there is a minimum infectious dose required for a susceptible host [100]. If this is the case, then even very low levels of contamination may be sufficient of cause disease. Weese and colleagues noted all samples of retail chicken that contained $C$. difficile were only positive on enrichment culture [142]; other studies that used detection methods with lower sensitivity may have under-reported the prevalence. Further, the possibility of laboratory contamination has been suggested as a potential explanation for evidence of $C$. difficile in food products [147], which can be dealt with by future researchers with the inclusion of additional highly discriminatory techniques, such as whole-genome sequencing.

More evidence is required to provide an epidemiological link between the consumption of contaminated food and the development of CDI and to establish whether foodborne transmission occurs in the community at a frequency to cause public health concern. However, the public health implications and actions required are unclear; if any level of exposure in the community might be enough to precipitate disease development, then prevention needs to be directed 'up the chain', with implications for the use of antimicrobials in production animals and handling of carcasses and meat processing. Public health messages may best be targeted at the susceptible population in the community, who may not always be easily identified and who may not be able to fully eliminate their risk through avoidance of potentially contaminated food. 


\section{Human Contacts}

The potential for asymptomatic carriers of $C$. difficile to shed the organism into the home environment and cause disease in other contacts has been demonstrated [148, 149], although to date there has been no evidence to support this route as a common mechanism for disease transmission in the community [5]. This potential may be amplified in the case of children under 2 years of age and their primary carers; close contact with faecal matter as part of caring for these children potentially exposes carers to a higher level of spores as asymptotic carriage in this group is high compared with other healthy individuals $[80,82]$. While the role of asymptomatic carriers is not well established, this is a plausible mechanism for transmission in the community, and contact with potential asymptomatic carriers, particularly young children, as a driver of CA-CDI should be explored further.

\section{LIMITATIONS}

There are several limitations when it comes to the interpretation of apparent increases in CA-CDI in the international literature. An increased awareness and subsequent ascertainment bias has been acknowledged as a potential factor influencing the increase in incidence [150]. It is logical that an increase in profile among physicians would result in increased testing and subsequent case ascertainment. In order for individual jurisdictions to monitor the impact of this bias on reporting, the proportion of positive cases should be reviewed alongside the raw numbers of requested tests. These data allow better interpretation of apparent increasing rates.
Another factor that needs to be taken into consideration is variable testing methodologies across different countries and changes to more sensitive testing methodologies over time [150]. The former may impact on the prevalence and, at least partially, account for variable rates. The latter may give the false appearance of increasing rates, when the reality is just more accurate detection methods. While evaluation of individual laboratory methods used in all studies was outside the scope of this review, differences were noted across various studies, which may account for some of the heterogeneity in the results.

Taking these limitations into account, it is still apparent that CA-CDI is increasing, despite almost certainly being underdiagnosed in the community $[49,151]$. Disease in the community can be severe, with one study showing CA-CDI cases were more likely to develop severe infection than HA-CDI [152]. Further, there is evidence of increasing the severity of disease among community cases, using outcomes such as colectomy [153] as a measure. While hospital-based estimates vary between facility and region, overall about one-third of CDI cases currently being detected in outpatients appear to be CA-CDI.

\section{CONCLUSION}

There is evidence of a growing incidence of CA-CDI worldwide, with cases in the community resulting in severe disease. While 'traditional' risk factors for CDI are well established, cases in the community lacking in traditional risk factors are being documented, suggesting such cases may have different risk factors for disease. Importantly, there is a paucity of knowledge around the epidemiology and risk factors for CA-CDI on a global scale. The available evidence 
suggests close contacts, the environment, animals (particularly production animals) and food as potential sources of this infection in the community. While there has been demonstrable plausibility for each of these routes of transmission for CA-CDI, no study has definitively identified one or a combination of these as the primary source of infection in the community. At this stage, the presence of $C$. difficile in these reservoirs does not conclusively prove a causative link; animals and food remain potential sources of CDI in the community. More research is required to quantify the burden of CA infection, and establish whether any of these suggested risk factors appear to have a causative role in CA-CDI.

To date, no studies have documented a transmission route between animals and humans. Similar strains have been found in humans and animals; however, while $C$. difficile is clearly a zoonotic organism, further research needs to be undertaken to establish the path of transmission. At best the evidence is patchy and further research is required. However, based on the available evidence, CDI, particularly in the community, sits firmly under the 'One Health' umbrella, in which human health, animal health and the environment are inextricably linked. CDI affects human and animal populations, although the links between the two require better definition and the messages around reducing risk in the community are not clear. Understanding the burden and drivers of disease in this setting is paramount.

CA-CDI is an emerging concern of public health significance. It is unlikely that the prevention and control of this organism within healthcare facilities will be achievable until the full dimensions of the problem, including what is happening outside of the hospital system, are known.

\section{ACKNOWLEDGMENTS}

All named authors meet the International Committee of Medical Journal Editors (ICMJE) criteria for authorship for this manuscript, take responsibility for the integrity of the work as a whole, and have given final approval for the version to be published.

No funding or sponsorship was received for this study or publication of this article.

Disclosures. Lauren E. Bloomfield and Thomas V. Riley both declare no personal, financial, commercial or academic conflicts of interest.

Compliance with Ethics Guidelines. This article is based on previously conducted studies and does not involve any new studies of human or animal subjects performed by any of the authors. Ethics approval was not required for this narrative review.

Open Access. This article is distributed under the terms of the Creative Commons Attribution-NonCommercial 4.0 International License (http://creativecommons.org/licenses/ by-nc/4.0/), which permits any noncommercial use, distribution, and reproduction in any medium, provided you give appropriate credit to the original author(s) and the source, provide a link to the Creative Commons license, and indicate if changes were made.

\section{REFERENCES}

1. Barbut F, Petit J-C. Epidemiology of Clostridium difficile-associated infections. Clin Microbiol Infect. 2001;7:405-10.

2. Wilcox MH. Clostridium difficile infection. Hospital Doctor. 2005;1-8. ISSN 02623145. 
3. Williams OM, Spencer RC. The management of Clostridium difficile infection. $\mathrm{Br}$ Med Bull. 2009;91(1):87-110.

4. Henderson DK, Palmore TN. Critical gaps in knowledge of the epidemiology and pathophysiology of healthcare-associated infections. Infect Control Hosp Epidemiol. 2010;31(Suppl 1):S4-6.

5. Leffler DA, Lamont JT. Not so nosocomial anymore: the growing threat of community-acquired Clostridium difficile. Am J Gastroenterol. 2012;107(1):96-8.

6. Poxton IR. The changing faces of Clostridium difficile: a personal reflection of the past 34 years. Anaerobe. 2013;24:124-7.

7. Hirschhorn LR, Trnka Y, Onderdonk A, Lee ML, Platt R. Epidemiology of community-acquired Clostridium difficile-associated diarrhea. J Infect Dis. 1994;169(1):127-33 (Epub 1994/01/01. Eng).

8. Kyne L, Merry C, O'Connell B, Keane C, O’Neill D. Community-acquired Clostridium difficile infection. J Infect. 1998;36:287-8.

9. Noren T, Akerlund T, Back E, Sjoberg L, Persson I, Alriksson I, et al. Molecular epidemiology of hospital-associated and community-acquired Clostridium difficile infection in a Swedish county. J Clin Microbiol. 2004;42(8):3635-43 (Epub 2004/08/07. ).

10. Riley TV, Wymer V, Bamford VW, Bowman RA. Clostridium difficile in general practice and community health. J Hyg. 1986;96(1):13-7 (Epub 1986/02/01).

11. Riley TV, Cooper M, Bell B, Golledge CL. Community-acquired Clostridium difficile-associated diarrhea. Clin Infect Dis. 1995;20(Suppl 2):S263-5 (Epub 1995/06/01).

12. Riley TV, Wetherall F, Bowman J, Mogyorosy J, Golledge CL. Diarrheal disease due to Clostridium difficile in general practice. Pathology. 1991;23(4):346-9 (Epub 1991/10/01).

13. Beaugerie L, Flahault A, Barbut F, Atlan P, Lalande $\mathrm{V}$, Cousin $\mathrm{P}$, et al. Antibiotic-associated diarrhoea and Clostridium difficile in the community. Aliment Pharmacol Ther. 2003;17(7):905-12 (Epub 2003/03/27).

14. McFarland LV, Beneda HW, Clarridge JE, Raugi GJ. Implications of the changing face of Clostridium difficile disease for health care practitioners. Am J Infect Control. 2007;35(4):237-53 (Epub 2007/05/ 08).
15. Kuijper EJ, Coignard B, Tull P. Emergence of Clostridium difficile-associated disease in North America and Europe. Clin Microbiol Inf. 2006;12(Suppl 6):2-18.

16. McDonald LC, Coignard B, Dubberke E, Song X, Horan T, Kutty PK. Recommendations for surveillance of Clostridium difficile-associated disease. Infect Cont Hosp Epidemiol. 2007;28(2):140-5 (Epub 2007/02/01).

17. European Centre for Disease Prevention and Control. European Surveillance of Clostridium difficile infections. Surveillance protocol version 2.2. Stockholm: ECDC; 2015. http://ecdc.europa. eu/en/publications/Publications/European-survei llance-clostridium-difficile.v2FINAL.pdf.

18. Jury LA, Sitzlar B, Kundrapu S, Cadnum JL, Summers KM, Muganda CP, et al. Outpatient healthcare settings and transmission of Clostridium difficile. PloS One. 2013;8(7):e70175 (Epub 2013/07/31).

19. Viscidi R, Willey S, Bartlett J. Isolation rates and toxigenic potential of Clostridium difficile isolates from various patient populations. Gastroenterology. 1981;81:5-9.

20. Gorbach S. Clostridium difficile settles in a nursing home. Hospital Practice. 1989;24(2):145-60.

21. Longtin Y, Paquet-Bolduc B, Gilca R, et al. Effect of detecting and isolating Clostridium difficile carriers at hospital admission on the incidence of c difficile infections: a quasi-experimental controlled study. JAMA Intern Med. 2016;176(6):796-804. doi:10. 1001/jamainternmed.2016.0177.

22. Eyre DW, Cule ML, Wilson DJ, Griffiths D, Vaughan $\mathrm{A}, \mathrm{O}^{\prime}$ Connor $\mathrm{L}$, et al. Diverse sources of $C$. difficile infection identified on whole-genome sequencing. N Engl J Med. 2013;369(13):1195-205.

23. Tattevin P, Buffet-Bataillon S, Donnio PY, Revest M, Michelet C. Clostridium difficile infections: do we know the real dimensions of the problem? Int $\mathrm{J}$ Antimicrob Agents. 2013;42(Suppl):S36-40 (Epub 2013/05/15).

24. Crobach MJ, Dekkers OM, Wilcox MH, Kuijper EJ. European Society of Clinical Microbiology and Infectious Diseases (ESCMID): data review and recommendations for diagnosing Clostridium difficile-infection (CDI). Clin Microbiol Infect. 2009;15(12):1053-66 (Epub 2009/11/26).

25. Cohen SH, Gerding DN, Johnson S, Kelly CP, Loo VG, McDonald LC, et al. Clinical practice guidelines for Clostridium difficile infection in adults: 2010 update by the society for healthcare epidemiology 
of America (SHEA) and the infectious diseases society of America (IDSA). Infect Cont Hosp Epidemiol. 2010;31(5):431-55 (Epub 2010/03/24).

26. Rupnik M, Wilcox MH, Gerding DN. Clostridium difficile infection: new developments in epidemiology and pathogenesis. Nat Rev Microbiol. 2009;7(7):526-36 (Epub 2009/06/17).

27. Gupta A, Khanna S. Community-acquired Clostridium difficile infection: an increasing public health threat. Infect Drug Resist. 2014;7:63-72 (Epub 2014/03/29).

28. Wilcox MH, Mooney L, Bendall R, Settle CD, Fawley WN. A case-control study of community-associated Clostridium difficile infection. J Antimicrob Chemother. 2008;62(2):388-96.

29. Hensgens MP, Keessen EC, Squire MM, Riley TV, Koene MG, de Boer E, et al. Clostridium difficile infection in the community: a zoonotic disease? Clin Microbiol Infect. 2012;18(7):635-45 (Epub 2012/04/28)

30. Alcala L, Martin A, Marin A, Sanchez-Somolinos M, Catalan P, Pelaez T, et al. The undiagnosed cases of Clostridium difficile infection in a whole nation: where is the problem? Clin Microbiol Infect. 2012;18:E204-13.

31. Bauer MP, Veenendaal D, Verhoef L, Bloembergen P, van Dissel JT, Kuijper E. Clinical and microbiological characteristics of community-onset Clostridium difficile infection in The Netherlands. Clin Microbiol Infect. 2009;15(12):1087-92.

32. Kyne L, Merry C, O'Connell B, Keane C, O’Neill D. Community-acquired Clostridium difficile infection. J Infect. 1998;36(3):287-8 (Epub 1998/11/20).

33. Jen MH, Saxena S, Bottle A, Pollok R, Holmes A, Aylin P. Assessment of administrative data for evaluating the shifting acquisition of Clostridium difficile infection in England. $J$ Hosp Infect. 2012;80(3):229-37 (Epub 2012/02/07).

34. Bauer MP, Notermans DW, van Benthem BH, Brazier JS, Wilcox MH, Rupnik $\mathrm{M}$, et al. Clostridium difficile infection in Europe: a hospital-based survey. Lancet ((London, England)). 2011;377(9759):63-73 (Epub 2010/11/19).

35. Khanna S, Pardi D. The growing incidence and severity of Clostridium difficile infection in inpatient and outpatient settings. Expert Rev Gastroenterol Heptol. 2010;4(4):409-16.

36. Kutty PK, Woods CW, Sena AC, Benoit SR, Naggie S, Frederick J, et al. Risk factors for and estimated incidence of community-associated Clostridium difficile infection, North Carolina, USA. Emerg Infect Dis. 2010;16(2):197-204 (Epub 2010/02/02).

37. Lessa FC. Community-associated Clostridium difficile infection: how real is it? Anaerobe. 2013;24:121-3.

38. Khanna S, Pardi DS, Aronson SL, Kammer PP, Baddour LM. Outcomes in community-acquired Clostridium difficile infection. Aliment Pharmacol Ther. 2012;35(5):613-8.

39. Allard R, Dascal A, Camara B, Letourneau J, Valiquette L. Community-acquired Clostridium difficile associated diarrhea, Montreal, 2005-2006: frequency estimates and their validity. Infect Control Hosp Epidemiol. 2011;32(10):1032-4 (Epub 2011/09/21).

40. Lambert PJ, Dyck M, Thompson LH, Hammond GW. Population-based surveillance of Clostridium difficile infection in Manitoba, Canada, by using interim surveillance definitions. Infect Cont Hosp Epidemiol. 2009;30(10):945-51 (Epub 2009/09/ 08).

41. Tan XQ, Verrall AJ, Jureen R, Riley TV, Collins DA, Lin RT, et al. The emergence of community-onset Clostridium difficile infection in a tertiary hospital in Singapore: a cause for concern. Int J Antimicrob Agents. 2014;43(1):47-51.

42. Slimings C, Armstrong P, Beckingham WD, Bull AL, Hall L, Kennedy KJ, et al. Increasing incidence of Clostridium difficile infection, Australia, 2011-2012. Med J Aust. 2014;200(5):272-6 (Epub 2014/03/20).

43. Jamal W, Pauline E, Rotimi V. A prospective study of community-associated Clostridium difficile infection in Kuwait: epidemiology and ribotypes. Anaerobe. 2015;35(Pt B):28-32 (Epub 2015/07/07).

44. Pituch H. Clostridium difficile is no longer just a nosocomial infection or an infection of adults. Int J Antimicrob Agents. 2009;33:S42-5.

45. Borriello SP. Pathogenesis of Clostridium difficile infection. J Antimicrob Chemother. 1998;41(Suppl C):13-9 (Epub 1998/06/18).

46. Bignardi GE. Risk factors for Clostridium difficile infection. J Hosp Infect. 1998;40(1):1-15.

47. Juneau C, Mendias EN, Wagal N, Loeffelholz M, Savidge T, Croisant $S$, et al. Community-acquired infection: awareness and clinical implications. JNP. 2013;9(1):1-6.

48. Kuntz JL, Chrischilles EA, Pendergast JF, Herwaldt LA, Polgreen PM. Incidence of and risk factors for community-associated Clostridium difficile infection: a nested case-control study. BMC Infect Dis. 2011;11:194. 
49. Kuijper EJ, van Dissel JT. Spectrum of Clostridium difficile infections outside health care facilities. $\mathrm{CMAJ}=$ journal de l'Association medicale canadienne. 2008;179(8):747-8 (Epub 2008/10/ 08).

50. Khanna S, Baddour LM, Huskins WC, Kammer PP, Faubion WA, Zinsmeister AR, et al. The epidemiology of Clostridium difficile infection in children: a population-based study. Clin Infect Dis. 2013;56(10):1401-6 (Epub 2013/02/15).

51. Naggie S, Frederick J, Pien BC, Miller BA, Provenzale DT, Goldberg KC, et al. Community-associated Clostridium difficile infection: experience of a veteran affairs medical center in southeastern USA. Infection. 2010;38(4):297-300 (Epub 2010/05/11).

52. Delaney JA, Dial S, Barkun A, Suissa S. Antimicrobial drugs and community-acquired Clostridium difficile-associated disease. UK. Emerg Infect Dis. 2007;13(5):761-3 (Epub 2007/06/08).

53. Holzbauer SM, Kemperman MM, Lynfield R. Death due to community-associated Clostridium difficile in a woman receiving prolonged antibiotic therapy for suspected lyme disease. Clin Infect Dis. 2010;51(3):369-70 (Epub 2010/07/06).

54. Kandel C, Moayedi Y, Bunce PE. A woman with community-acquired Clostridium difficile infection. $\mathrm{CMAJ}=$ journal de l'Association medicale canadienne. 2012;184(12):1383-5 (Epub 2012/07/ 25).

55. Heslop OD, Roye-Green K, Coard K, Mulvey MR. A unique strain of community-acquired Clostridium difficile in severe complicated infection and death of a young adult. BMC Infect Dis. 2013;13:299-302.

56. Deshpande A, Pasupuleti V, Thota P, Pant C, Rolston DD, Sferra TJ, et al. Community-associated Clostridium difficile infection and antibiotics: a meta-analysis. J Antimicrob Chemother. 2013;68(9):1951-61.

57. Slimings C, Riley TV. Antibiotics and hospital-acquired Clostridium difficile infection: update of systematic review and meta-analysis. J Antimicrob Chemother. 2014;69(4):881-91. doi:10.1093/jac/dkt477 (Epub 2013/12/08).

58. Wilcox MH, Mooney L, Bendall R, Settle CD, Fawley WN. A case-control study of community-associated Clostridium difficile infection. J Antimicrob Chemother. 2008;62(2):388-96.

59. Centers for Disease Control and Prevention (CDC). Surveillance for community-associated Clostridium difficile-Connecticut, 2006. MMWR Morbidity and mortality weekly report. 2008;57(13):340-343 (Epub 2008/04/04).
60. Chitnis AS, Holzbauer SM, Belflower RM, Winston LG, Bamberg WM, Lyons C, et al. Epidemiology of community-associated Clostridium difficile infection, 2009 through 2011. JAMA Intern Med. 2013;173(14):1359-67.

61. McFarland LV, Clarridge JE, Beneda HW, Raugi GJ. Fluoroquinolone use and risk factors for Clostridium difficile-associated disease within a Veterans Administration health care system. Clin Infect Dis. 2007;45(9):1141-51 (Epub 2007/10/06).

62. Dial S, Delaney J, Barkan A, Suissa S. Use of gastric acid-suppressive agents and the risk of community-acquired Clostridium difficile-associated disease. J Am Med Assoc. 2005;294(23):2989-95.

63. Esposito A, Agraharkar M, Pitts W. Community-acquired, antibiotic-unassociated, Clostridium difficile colitis: report of four patients. Infect Dis Clin Pract. 1997;6(6):385-90.

64. Collins CE, Ayturk MD, Flahive JM, Emhoff TA, Anderson FA, Jr., Santry HP. Epidemiology and outcomes of community-acquired Clostridium difficile infections in Medicare beneficiaries. J Am Coll Surg. 2014;218(6):1141-7 e1 (Epub 2014/04/ 24).

65. Dial S, Delaney JAC, Barkun AN, Suissa S. Use of gastric acid-suppressive agents and the risk of community-acquired Clostridium difficile-associated disease. J Am Med Assoc. 2005;293(23):2989-95.

66. Dial S, Delaney JA, Schneider V, Suissa S. Proton pump inhibitor use and risk of community-acquired Clostridium difficile-associated disease defined by prescription for oral vancomycin therapy. $\mathrm{CMAJ}=$ journal de l'Association medicale canadienne. 2006;175(7):745-8 (Epub 2006/09/27).

67. Freedberg DE, Abrams JA. Clostridium difficile infection in the community: are proton pump inhibitors to blame? WJG. 2013;19(40):6710-3.

68. Naggie S, Miller BA, Zuzak KB, Pence BW, Mayo AJ, Nicholson BP, et al. A case-control study of community-associated Clostridium difficile infection: no role for proton pump inhibitors. Am J Med. 2011;124(3):276 e1-7 (Epub 2011/03/15).

69. Clooney AG, Bernstein CN, Leslie WD, Vagianos K, Sargent M, Laserna-Mendieta EJ, et al. A comparison of the gut microbiome between long-term users and non-users of proton pump inhibitors. Aliment Pharmacol Ther. 2016;43(9):974-84 (Epub 2016/03/01).

70. Imhann F, Bonder MJ, Vich Vila A, Fu J, Mujagic Z, Vork L, et al. Proton pump inhibitors affect the gut microbiome. Gut. 2016;65(5):740-8 (Epub 2015/12/15). 
71. Seto CT, Jeraldo P, Orenstein R, Chia N, DiBaise JK. Prolonged use of a proton pump inhibitor reduces microbial diversity: implications for Clostridium difficile susceptibility. Microbiome. 2014;2:42 (Epub 2014/11/27. eng).

72. Ricciardi R, Ogilvie JW Jr, Roberts PL, Marcello PW, Concannon TW, Baxter NN. Epidemiology of Clostridium difficile colitis in hospitalized patients with inflammatory bowel diseases. Dis Colon Rectum. 2009;52(1):40-5 (Epub 2009/03/11).

73. Cojocariu C, Stanciu C, Stoica O, Singeap AM, Sfarti $\mathrm{C}$, Girleanu I, et al. Clostridium difficile infection and inflammatory bowel disease. Turk J Gastroenterol. 2014;25(6):603-10 (Epub 2015/01/21).

74. Stoica O, Trifan A, Cojocariu C, Girleanu I, Maxim $\mathrm{R}$, Stanciu MC. Incidence and risk factors of Clostridium difficile infection in patients with inflammatory bowel disease. Revista medico-chirurgicala a Societatii de Medici si Naturalisti din Iasi. 2015;119(1):81-6 (Epub 2015/05/15).

75. Cosnes J, Cattan S, Blain A, Beaugerie L, Carbonnel F, Parc R, et al. Long-term evolution of disease behavior of Crohn's disease. Inflamm Bowel Dis. 2002;8(4):244-50 (Epub 2002/07/20).

76. Goodhand JR, Alazawi W, Rampton DS. Systematic review: Clostridium difficile and inflammatory bowel disease. Aliment Pharmacol Ther. 2011;33(4):428-41.

77. Patriarchi F, Rolla M, Maccioni F, Menichella A, Scacchi C, Ambrosini A, et al. Clostridium difficile-related pancolitis in lung-transplanted patients with cystic fibrosis. Clin Transplant. 2011;25(1):E46-51 (Epub 2010/07/21).

78. Kyne L, Sougioultzis S, McFarland LV, Kelly CP. Underlying disease severity as a major risk factor for nosocomial Clostridium difficile diarrhea. Infect Control Hosp Epidemiol. 2002;23(11):653-9.

79. Hall I, O’Toole E. Intestinal flora in new-born infants: with a description of a new pathogenic anaerobe, Bacillus difficilis. Am J Dis Child. 1935;49:390-402.

80. Rousseau C, Poilane I, De Pontual L, Maherault AC, Le Monnier A, Collignon A. Clostridium difficile carriage in healthy infants in the community: a potential reservoir for pathogenic strains. Clin Infect Dis. 2012;55(9):1209-15.

81. Enoch DA, Butler MJ, Pai S, Aliyu SH, Karas JA. Clostridium difficile in children: colonisation and disease. J Infect. 2011;63(2):105-13 (Epub 2011/06/15).
82. Jangi S, Lamont JT. Asymptomatic colonization by Clostridium difficile in infants: implications for disease in later life. J Pediatric Gastroenterol Nutr. 2010;51(1):2-7 (Epub 2010/06/01).

83. Soes LM, Holt HM, Bottiger B, Nielsen HV, Andreasen $\mathrm{V}$, Kemp $\mathrm{M}$, et al. Risk factors for Clostridium difficile infection in the community: a case-control study in patients in general practice, Denmark, 2009-2011. Epidemiol Infect. 2014;142(7):1437-48 (Epub 2013/10/01).

84. Toltzis P, Zaoutis T. Community-associated Clostridium difficile infection in children. Clin Infect Dis. 2013;57(12):1673-5 (Epub 2013/09/21).

85. Fellmeth G, Yarlagadda S, Iyer S. Epidemiology of community-onset Clostridium difficile infection in a community in the South of England. J Infect Pub Health. 2010;3(3):118-23 (Epub 2010/09/28).

86. Gutierrez RL, Riddle MS, Porter CK. Epidemiology of Clostridium difficile infection among active duty United States military personnel (1998-2010). BMC Infect Dis. 2013;13:609 (Epub 2014/01/01).

87. Chernak E, Weltman A, McDonald L, Wiggs L, Killgore G, Thompson A, et al. Severe Clostridium difficile-associated disease in populations previously at low risk-four states, 2005. MMWR. 2005;54(47):1201-5 (Epub 2005/12/02).

88. Rouphael NG, O’Donnell JA, Bhatnagar J, Lewis F, Polgreen PM, Beekmann $\mathrm{S}$, et al. Clostridium difficile-associated diarrhea: an emerging threat to pregnant women. Am J Obstet Gynecol. 2008;198(6):635 e1-6 (Epub 2008/04/09).

89. Denno DM, Shaikh N, Stapp JR, Qin X, Hutter CM, Hoffman V, et al. Diarrhea etiology in a pediatric emergency department: a case control study. Clin Infect Dis. 2012;55(7):897-904 (Epub 2012/06/16).

90. Otten AM, Reid-Smith RJ, Fazil A, Weese JS. Disease transmission model for community-associated Clostridium difficile infection. Epidemiol Infect. 2010;138(6):907-14.

91. Alam MJ, Anu A, Walk ST, Garey KW. Investigation of potentially pathogenic Clostridium difficile contamination in household environs. Anaerobe. 2014;27:31-3 (Epub 2014/03/25).

92. Weese JS, Finley R, Reid-Smith RR, Janecko N, Rousseau J. Evaluation of Clostridium difficile in dogs and the household environment. Epidemiol Infect. 2010;138(8):1100-4.

93. Al Saif N, Brazier JS. The distribution of Clostridium difficile in the environment of South Wales. J Med Microbiol. 1996;45(2):133-7. 
94. Simango C. Prevalence of Clostridium difficile in the environment in a rural community in Zimbabwe. Trans R Soc Trop Med Hyg. 2006;100:1146-50.

95. Levett PN. Clostridium difficile in habitats other than the human gastro-intestinal tract. J Infect. 1986;12(3):253-63 (Epub 1986/05/01. eng).

96. Zidaric V, Beigot S, Lapajne S, Rupnik M. The occurrence and high diversity of Clostridium difficile genotypes in rivers. Anaerobe. 2010;16(4):371-5 (Epub 2010/06/15).

97. Nikaeen M, Aghili Dehnavi H, Hssanzadeh A, Jalali M. Occurrence of Clostridium difficile in two types of wastewater treatment plants. J Formos Med Assoc $=$ Taiwan yi zhi. 2015;114(7):663-5 (Epub 2015/05/10).

98. Romano V, Pasquale V, Krovacek K, Mauri F, Demarta A, Dumontet S. Toxigenic Clostridium difficile PCR ribotypes from wastewater treatment plants in southern Switzerland. Appl Environ Microbiol. 2012;78(18):6643-6.

99. Viau E, Peccia J. Survey of wastewater indicators and human pathogen genomes in biosolids produced by class A and class B stabilization treatments. Appl Environ Microbiol. 2009;75(1):164-74 (Epub 2008/11/11).

100. Hensgens M, Keessen EC, Squire M, Riley TV, Koene $\mathrm{M}$, de Boer $\mathrm{E}$, et al. Clostridium difficile infection in the community: a zoonotic disease? Clin Microbiol Infect. 2012;18(7):635-45.

101. Songer JG. Clostridia as agents of zoonotic disease. Vet Microbiol. 2010;140(3-4):399-404 (Epub 2009/08/18).

102. Arroyo LG, Kruth SA, Willey BM, Staempfli HR, Low DE, Weese JS. PCR ribotyping of Clostridium difficile isolates originating from human and animal sources. J Med Microbiol. 2005;54(Pt 2):163-6 (Epub 2005/01/28).

103. Keel K, Brazier JS, Post KW, Weese S, Songer JG. Prevalence of PCR ribotypes among Clostridium difficile isolates from pigs, calves, and other species. J Clin Microbiol. 2007;45(6):1963-4 (Epub 2007/04/13).

104. Rupnik M, Widmer A, Zimmermann O, Eckert C, Barbut F. Clostridium difficile toxinotype V, ribotype 078, in animals and humans. J Clin Microbiol. 2008;46(6):2146 (Epub 2008/04/18).

105. Pirs T, Ocepek M, Rupnik M. Isolation of Clostridium difficile from food animals in Slovenia. J Med Microbiol. 2008;57(Pt 6):790-2 (Epub 2008/05/16).
106. Debast SB, van Leengoed LA, Goorhuis A, Harmanus C, Kuijper EJ, Bergwerff AA. Clostridium difficile PCR ribotype 078 toxinotype $\mathrm{V}$ found in diarrhoeal pigs identical to isolates from affected humans. Environ Microbiol. 2009;11(2):505-11 (Epub 2009/02/07).

107. Avbersek J, Janezic S, Pate M, Rupnik M, Zidaric V, Logar K, et al. Diversity of Clostridium difficile in pigs and other animals in Slovenia. Anaerobe. 2009;15(6):252-5 (Epub 2009/07/28).

108. George WL, Rolfe RD, Sutter VL, Finegold SM. Diarrhea and colitis associated with antimicrobial therapy in man and animals. Am J Clin Nutr. 1979;32(1):251-7 (Epub 1979/01/01).

109. Weese JS, Armstrong J. Outbreak of Clostridium difficile-associated disease in a small animal veterinary teaching hospital. J Vet Intern Med/Am Coll Vet Intern Med. 2003;17(6):813-6 (Epub 2003/12/09).

110. Songer JG, Post KW, Larson DVM, Jost H, Glock R. Infection of neonatal swine with Clostridium difficile. Swine Health Prod. 2000;8(4):185-9.

111. Kiss D, Bilkei G. A new periparturient disease in Eastern Europe, Clostridium difficile causes postparturient sow losses. Theriogenology. 2005;63(1):17-23 (Epub 2004/12/14).

112. Yaeger M, Funk N, Hoffman L. A survey of agents associated with neonatal diarrhea in Iowa swine including Clostridium difficile and porcine reproductive and respiratory syndrome virus. J Vet Diagn Investig. 2002;14(4):281-7 (Epub 2002/08/ 03).

113. Rodriguez-Palacios A, Borgmann S, Kline TR, LeJeune JT. Clostridium difficile in foods and animals: history and measures to reduce exposure. Anim Health Res Rev/Conf Res Work Anim Dis. 2013;14(1):11-29.

114. Blanco JL, Alvarez-Perez S, Garcia ME. Is the prevalence of Clostridium difficile in animals underestimated? Vet J. 2013;197(3):694-8. doi:10. 1016/j.tvjl.2013.03.053 (Epub 2013/07/30).

115. Weese JS. Clostridium difficile in food-innocent bystander or serious threat? Clin Microbiol Infect. 2010;16(1):3-10.

116. Norman KN, Harvey RB, Scott HM, Hume ME, Andrews K, Brawley AD. Varied prevalence of Clostridium difficile in an integrated swine operation. Anaerobe. 2009;15(6):256-60 (Epub 2009/09/26).

117. Weese JS, Wakeford T, Reid-Smith R, Rousseau J, Friendship R. Longitudinal investigation of 
Clostridium difficile shedding in piglets. Anaerobe. 2010;16(5):501-4 (Epub 2010/08/17).

118. Weese JS. Clostridium difficile in food-innocent bystander or serious threat? Clin Microbiol Infect. 2010;16(1):3-10 (Epub 2009/12/17).

119. Keessen EC, Gaastra W, Lipman LJ. Clostridium difficile infection in humans and animals, differences and similarities. Vet Microbiol. 2011;153(3-4):205-17.

120. Dibner JJ, Richards JD. Antibiotic growth promoters in agriculture: history and mode of action. Poult Sci. 2005;84(4):634-43 (Epub 2005/04/23).

121. Wegener HC. Antibiotics in animal feed and their role in resistance development. Curr Opin Microbiol. 2003;6(5):439-45 (Epub 2003/10/24).

122. Songer JG. The emergence of Clostridium difficile as a pathogen of food animals. Anim Health Res Rev/ Conf Res Work Anim Dis. 2004;5(2):321-6 (Epub 2005/06/30).

123. Nagy J, Bilkei G. Neonatal piglet losses associated with Escherichia coli and Clostridium difficile infection in a Slovakian outdoor production unit. Vet J (London, England: 1997). 2003;166(1):98-100 (Epub 2003/06/06).

124. Hopman NE, Keessen EC, Harmanus C, Sanders IM, van Leengoed LA, Kuijper EJ, et al. Acquisition of Clostridium difficile by piglets. Vet Microbiol. 2011;149(1-2):186-92 (Epub 2010/11/30).

125. Keessen EC, Donswijk CJ, Hol SP, Hermanus C, Kuijper EJ, Lipman LJ. Aerial dissemination of Clostridium difficile on a pig farm and its environment. Environ Res. 2011;111(8):1027-32 (Epub 2011/10/22).

126. Rodriguez C, Avesani V, Van Broeck J, Taminiau B, Delmee M, Daube G. Presence of Clostridium difficile in pigs and cattle intestinal contents and carcass contamination at the slaughterhouse in Belgium. Int J Food Microbiol. 2013;166(2):256-62 (Epub 2013/08/27).

127. Medina-Torres CE, Weese JS, Staempfli HR. Prevalence of Clostridium difficile in horses. Vet Microbiol. 2011;152(1-2):212-5 (Epub 2011/05/17).

128. Rodriguez C, Taminiau B, Van Broeck J, Avesani V, Delmee M, Daube G. Clostridium difficile in young farm animals and slaughter animals in Belgium. Anaerobe. 2012;18(6):621-5 (Epub 2012/10/09).

129. Keessen EC, Harmanus C, Dohmen W, Kuijper EJ, Lipman LJ. Clostridium difficile infection associated with pig farms. Emerg Infect Dis. 2013;19(6):1032-4 (Epub 2013/06/06).
130. Clooten J, Kruth S, Arroyo L, Weese JS. Prevalence and risk factors for Clostridium difficile colonization in dogs and cats hospitalized in an intensive care unit. Vet Microbiol. 2008;129(1-2):209-14 (Epub 2008/01/01).

131. Schneeberg A, Rupnik M, Neubauer H, Seyboldt C. Prevalence and distribution of Clostridium difficile PCR ribotypes in cats and dogs from animal shelters in Thuringia, Germany. Anaerobe. 2012;18(5):484-8 (Epub 2012/09/07).

132. Wetterwik KJ, Trowald-Wigh G, Fernstrom LL, Krovacek K. Clostridium difficile in faeces from healthy dogs and dogs with diarrhea. Acta Vet Scand. 2013;55:23 (Epub 2013/03/19).

133. Bandelj P, Trilar T, Blagus R, Ocepek M, Rousseau J, Weese JS, et al. Prevalence and molecular characterization of Clostridium difficile isolated from European Barn Swallows (Hirundo rustica) during migration. BMC Vet Res. 2014;10:40 (Epub 2014/02/11).

134. Silva RO, D'Elia ML, Tostes Teixeira EP, Pereira PL, de Magalhaes Soares DF, Cavalcanti AR, et al. Clostridium difficile and Clostridium perfringens from wild carnivore species in Brazil. Anaerobe. 2014;28:207-11 (Epub 2014/07/01).

135. Rodriguez-Palacios A, Staempfli HR, Duffield T, Weese JS. Clostridium difficile in retail ground meat. Canada. Emerg Infect Dis. 2007;13(3):485-7.

136. Limbago B, Thompson AD, Greene SA, MacCannell D, MacGowan CE, Jolbitado B, et al. Development of a consensus method for culture of Clostridium difficile from meat and its use in a survey of U.S. retail meats. Food Microbiol. 2012;32(2):448-51 (Epub 2012/09/19).

137. Visser M, Sephri S, Olson N, Du T, Mulvey MR, Alfa MJ. Detection of Clostridium difficile in retail ground meat products in Manitoba. Can J Infect Dis Med Microbiol = Journal canadien des maladies infectieuses et de la microbiologie medicale/AMMI Canada. 2012 Spring;23(1):28-30 (Epub 2013/03/ 02).

138. Bouttier S, Barc M-C, Felix B, Lambert S, Collignon A, Barbut F. Clostridium difficile in ground meat, France. Emerg Infect Dis. 2010;16(4):733-5.

139. de Boer E, Zwartkruis-Nahuis A, Heuvelink AE, Harmanus C, Kuijper EJ. Prevalence of Clostridium difficile in retailed meat in the Netherlands. Int $\mathrm{J}$ Food Microbiol. 2011;144(3):561-4.

140. Killgore GE, Limbago BM, McDonald LC, Songer JG, Thompson AD, Trinh HT. Clostridium difficile in retail meat products, USA, 2007. Emerg Infect Dis. 2009;15:819+. (English). 
141. Metcalf D, Reid-Smith RJ, Avery BP, Weese JS. Prevalence of Clostridium difficile in retail pork. Can Vet J. 2010;51(8):873-6.

142. Weese JS, Reid-Smith RJ, Avery BP, Rousseau J. Detection and characterization of Clostridium difficile in retail chicken. Lett Appl Microbiol. 2010;50(4):362-5.

143. Jobstl M, Heuberger S, Indra A, Nepf R, Kofer J, Wagner M. Clostridium difficile in raw products of animal origin. Int $\mathrm{J}$ Food Microbiol. 2010;138(1-2):172-5.

144. Quesada-Gomez C, Mulvey MR, Vargas P, Gamboa-Coronado Mdel M, Rodriguez C, Rodriguez-Cavillini E. Isolation of a toxigenic and clinical genotype of Clostridium difficile in retail meats in Costa Rica. J Food Protect. 2013;76(2):348-51 (Epub 2013/02/26).

145. Deng K, Plaza-Garrido A, Torres JA, Paredes-Sabja D. Survival of Clostridium difficile spores at low temperatures. Food Microbiol. 2015;46:218-21 (Epub 2014/12/06).

146. Rodriguez-Palacios A, Reid-Smith RJ, Staempfli HR, Weese JS. Clostridium difficile survives minimal temperature recommended for cooking ground meats. Anaerobe. 2010;16(5):540-2 (Epub 2010/05/22).

147. Marsh JW. Counterpoint: is Clostridium difficile a food-borne disease? Anaerobe. 2013;21:62-3.
148. Pepin J, Gonzales M, Valiquette L. Risk of secondary cases of Clostridium difficile infection among household contacts of index cases. J Infect. 2012;64(4):387-90.

149. Kim KH, Fekety R, Batts DH, Brown D, Cudmore M, Silva J Jr, et al. Isolation of Clostridium difficile from the environment and contacts of patients with antibiotic-associated colitis. J Infect Dis. 1981;143(1):42-50 (Epub 1981/01/01. eng).

150. Freeman J, Bauer MP, Baines SD, Corver J, Fawley $\mathrm{WN}$, Goorhuis B, et al. The changing epidemiology of Clostridium difficile infections. Clin Microbiol Rev. 2010;23(3):529-49.

151. Dawson LF, Valiente E, Wren BW. Clostridium difficile-a continually evolving and problematic pathogen. Infect Genet Evol J Mol Epidemiol Evol Genet Infect Dis. 2009;9(6):1410-7.

152. Ogielska M, Lanotte P, Le Brun C, Valentin AS, Garot D, Tellier AC, et al. Emergence of community-acquired Clostridium difficile infection: the experience of a French hospital and review of the literature. Int J Infect Dis. 2015;37:36-41 (Epub 2015/06/21).

153. McMullen KM, Mayfield JL, Abdul-Hakim A, Warren DK, Dubberke ER. Assessing colectomies due to Clostridium difficile infection: increases in the community, but not in the referral center. Am J Infect Control. 2012;40(8):778-80 (Epub 2012/01/ 31). 